Revista Aspas

ppgac - USP

Artigo

\title{
NEOLIBERALISMO E MODOS DE PRODUÇÃO TEATRAL NO BRASIL: DA PÓS-DITADURA AO NEOFASCISMO*
}

\author{
NEOLIBERALISM AND MODES OF THEATER PRODUCTION IN BRAZIL: \\ FROM POST-DICTATORSHIP TO NEO-FASCISM
}

\section{NEOLIBERALISMO Y MODOS DE PRODUCCIÓN TEATRAL EN BRASIL: DE LA POSDICTADURA AL NEOFASCISMO}

\section{Gustavo Guenzburger}

Gustavo Guenzburger

é artista, ativista, pesquisador e professor de teatro e literatura.

Em 2020 foi pesquisador fellow no Centre for Global Theatre Histories \& Developing Theatre Project, da Universidade LMU de Munique, com bolsa do European Research Council, período no qual foi finalizado o presente trabalho (Grant Agreement n. 694559 - DevelopingTheatre). De 2015 a 2019 lecionou e desenvolveu no PPGAC da UNIRIO uma pesquisa de pósdoutorado com Bolsa Nota 10 da FAPERJ (desde 2016), cujos resultados são, alguns deles, sintetizados aqui. Em 2014, realizou estágio-sanduíche na Universidade Paris 3, como parte de seu doutorado na UERJ. 


\section{Resumo}

$O$ presente trabalho investiga relações entre $\mathrm{o}$ teatro brasileiro e a ideologia neoliberal. Para tanto, o texto faz um breve sumário de alguns modos de produção, circuitos teatrais e políticas culturais atuantes na cidade do Rio de Janeiro, desde o fim da ditadura militar até a presente ascensão do neofascismo. A hipótese a ser discutida é que, durante esse período, o meio teatral tem um papel importante na construção de sua própria crise, ao assumir para si alguns princípios e práticas do neoliberalismo.

Palavras-chave: Modos de produção teatrais, políticas culturais, sociologia do teatro, teatro carioca

\section{Abstract}

This work explores the relationship between Brazilian theatre and neoliberal ideology. To this end, the text makes a brief summary of some modes of production, theatrical circuits and cultural policies that have been active in the city of Rio de Janeiro since the end of the military dictatorship until the recent rise of neo-fascism. The hypothesis to be discussed is that, during this period, the theatrical environment has an important role in the construction of its own crisis, when it assumes for itself some principles and practices of neoliberalism.

Keywords: Theatrical modes of production, cultural policies, sociology of theatre, Rio de Janeiro Theatre 
O teatro no Brasil passa por uma crise profunda que começou muito antes da pandemia de Covid-19. Desde 2016, a ressurgência de ideologias regressivas faz com que artistas e espetáculos sejam alvo de censura e perseguição pelo Estado e por setores da sociedade. Nesse aspecto, a cultura se une à educação e à pesquisa científica, que também têm suas verbas cortadas e suas instituições atacadas.

Mas se quisermos compreender as origens da crise teatral, também é necessário ir muito além da recente virada reacionária brasileira. É preciso que se estude as relações do teatro com dispositivos socioeconômicos, institucionais e ideológicos que são hoje alvo de ataques, mas que já vinham nos últimos 40 anos engendrando o ambiente de crise. Se o teatro foi um foco de resistência da sociedade ao autoritarismo do regime militar, no período seguinte de democracia ele veio perdendo gradativamente seu público, sua importância social, sua capacidade política e, mais recentemente, seus recursos estatais. Hoje, o teatro não consegue mais fazer frente a governos e movimentos fascistas. Atacado em seus meios materiais, mal resiste ao desmonte das políticas culturais que, até então, vinham ao menos amenizando seu lento processo de precarização e desprofissionalização.

A sistematização de políticas culturais no Brasil floresceu nas décadas de 80 e 90, a final e logo após a ditadura, portanto em um período dominado pelas ideias de globalização, Estado mínimo e livre competição. Ao assumir práticas neoliberais, o Estado brasileiro demarcou limites socioeconômicos e ideológicos para as políticas culturais que ele mesmo buscava implementar. Apesar de algumas tentativas de democratização no início do século $\mathrm{XXI}$, as políticas neoliberais moldaram muito do fazer teatral e até hoje ajudam a perenizar no teatro o legado ideológico do pós-ditadura.

O presente trabalho analisa as relações que o teatro do Rio de Janeiro vem mantendo nos últimos 40 anos com esse tipo de política estatal e com a ideologia que a gera, através de um brevíssimo histórico de alguns de seus modos de produção. A hipótese a ser discutida é de que o meio teatral tem um papel importante na construção de sua própria crise, ao assumir para si alguns pressupostos do neoliberalismo. 


\section{Modos de produção e a formação de nichos teatrais no Rio de Janeiro}

\section{Teatro-arte ${ }^{1}$ por bilheteria, simbiose TV - Teatro}

Diferentemente da maioria dos países, a profissionalização do teatro de arte durante a segunda metade do século XX não aconteceu no Brasil a partir de políticas de mecenato público ou privado, mas graças a uma solução de conciliação com a emergente indústria televisiva nacional. Ainda no final da década de 50 , artistas do chamado teatro moderno, que também foram pioneiros da televisão, haviam descoberto as vantagens do uso de suas imagens na tela para turbinar suas atividades no palco. Em três décadas, essa simbiose se amplifica e se complexifica de tal modo que chega a criar, pela primeira vez, um mercado de bilheteria para o teatro de arte no Rio de Janeiro. Tal mercado angaria tamanho público para o teatro "sério" ou "teatrão", que chega a alcançar certa independência em relação aos nomes famosos. Seus espetáculos são montagens de peças de "valor literário" que navegam dentro de um espectro realista de encenação; seu público alvo é uma burguesia de classe média em ascensão que frequenta teatros da zona sul e centro da cidade, em busca de aprendizagem e atualização cultural. $O$ auge desse fenômeno foram os anos 70 e 80 , e sua decadência se inicia no final da ditadura, quando o Rio conhece uma explosão de violência urbana e quando a simbiose com a TV se transforma em concorrência. Nessa fase final, a telenovela tende a capturar para si a totalidade do público consumidor de dramaturgia realista.

A medida do regime de legitimação da TV é a fama. Mas para os artistas do duplo nicho TV-teatro, muitas vezes essa medida é a capacidade de equilibrar o sucesso nas telas com trabalhos "de qualidade" nos palcos. Além da promessa de estrelato e de altos salários, a televisão é o único meio em que artistas podem ter acesso a contratação formal e direitos trabalhistas

\footnotetext{
'Na esteira do termo consagrado por Stanislavski, a ideia de um "teatro de arte" marca historiograficamente um certo ideal de teatro moderno e literário. No presente texto, na falta de um nome melhor, os termos teatro-arte e teatro de arte são utilizados para designar qualquer teatro com pretensões para além do mero entretenimento, seja na época e estilo que for.
} 
- apenas Globo -, ou seja, é a única perspectiva de profissionalização completa. Por conta disso, a conciliação entre excelência artística e exposição industrial se transformou em um plano de carreira a ser perseguido pelos artistas do Rio de Janeiro. Mesmo quando inconscientemente, esse padrão influencia de tal modo as mentalidades, que acaba por hierarquizar, em um sistema verticalizado, os vários nichos do teatro de arte do Rio, transformando-os em castas. Quanto mais distante da fama televisiva, mais na base da pirâmide se está.

\section{Captação via Lei Rouanet e outras leis de fomento indireto}

A partir da segunda metade da década de 80 , o teatro de arte buscou soluções artísticas e econômicas para enfrentar a crise de bilheteria e a competição com a TV. Através da pesquisa cênica, uma nova geração de artistas tentou se descolar da estética realista, já capturada e banalizada pela teledramaturgia. À procura de novos mercados, esse teatro de novas linguagens se voltava para o patrocínio de empresas privadas, interessadas em conectar suas marcas a uma imagem de inovação. Ainda não havia políticas públicas sistemáticas de fomento cultural no País.

As leis de incentivo foram criadas nessa época justamente no intuito de preencher essa lacuna e viabilizar o novo mercado das experiências artísticas, direcionando-as ainda mais ao marketing cultural. Mas o contexto do período pós-ditadura atrelou a gênese dessa legislação cultural ao embate de duas forças contraditórias: a urgência de uma política de Estado para a cultura e o receio de um possível dirigismo governamental. Nos anos 80 , o ideal de Estado mínimo se fortalecia mundialmente e mais ainda no Brasil, onde até mesmo setores de esquerda temiam a intromissão cultural de um Estado saindo de 21 anos de ditadura fascista. Além disso, a crise econômica, a hiperinflação e a dívida externa galopantes amarravam as possibilidades de investimento estatal em qualquer área.

Esse contexto paradoxal onde a necessidade de políticas culturais se choca com o desprestígio de um Estado autoritário e falido está na origem da especificidade e da ambiguidade da principal legislação cultural brasileira. Sua 
compreensão histórica é fundamental para a identificação do legado do pósditadura na forma de se fazer teatro no Brasil.

Naquele momento ideológico neoliberal, a ideia de marketing cultural parecia solucionar o impasse, através da atração de recursos privados para a cultura. Inspirada no modelo estadunidense, a opção brasileira pelo incentivo fiscal visava facilitar o investimento e a participação da sociedade civil no mercado cultural. Mas desenvolvimentos posteriores na implementação da legislação de incentivo distorceram sua origem ideológica liberal e consolidaram, na prática, um sistema clientelista, racista e excludente, que só existe no Brasil. Na chamada "Lei Rouanet', empresas muito ricas patrocinam projetos que são totalmente pagos pelo governo, através do mecanismo da renúncia fiscal integral.

Neste mecanismo em que o dinheiro é público mas a seleção dos projetos é privada, o cerceamento e a normatização de temáticas, modos, sujeitos e experiências teatrais são tão dissimulados quanto a origem estatal de seus recursos. Com o tempo, esquecida a promessa de subvenção à experiência de linguagens, empresas passaram a usar a Lei Rouanet para patrocinar espetáculos com vedetes do star-system televisivo. O teatro-arte que aceitou fazer parte desse sistema elitista foi perdendo gradativamente sua plateia, seu lugar na esfera pública e finalmente seus patrocínios, a partir do momento que a Rouanet se volta aos grandes musicas do estilo Broadway.

Os trinta anos de Lei Rouanet estabelecem, enfim, um certo elo de ligação institucional entre o período militar e a censura que volta hoje aos palcos brasileiros. O mecanismo seletivo da Rouanet, que sempre usou critérios "de mercado" para disfarçar uma censura socioeconômica no acesso a verbas de cultura, a partir de 2019 passou a ser usado abertamente por gestores fundamentalistas para direcionar esse veto a determinadas obras e artistas. 
3. Editais e outras formas curatoriais de fomento direto

Durante a primeira década do século XXI, apesar do fracasso nas tentativas de implementação de uma nova e mais democrática legislação federal de apoio à cultura, na prática, muita coisa vinha se transformando pela conscientização cada vez maior da sociedade em relação ao papel do Estado como fomentador. A federação, estados e municípios foram assumindo assim gradativamente seu papel na escolha dos projetos artísticos e culturais a serem subvencionados. Experiências de outros países como a França e um certo abrandamento temporário da ideologia neoliberal justificaram, no Brasil, a abertura de editais públicos locais para a produção cultural. No Rio de Janeiro, uma política de editais anuais resultou na sistematização do fomento direto a formas de teatro menos voltadas para a bilheteria. A partir daí, grupos, diretores desconhecidos e artistas jovens e inovadores que haviam trabalhado durante a década de 90 sem o auxílio da Lei Rouanet ou de qualquer outro fomento, começaram finalmente a profissionalizar seus espetáculos de pesquisa de linguagem.

O foco na inovação cênica incentivou, nesse tipo curatorial de fomento, um perfil carioca individualista de artistas-empreendedores. Grupos do Rio em geral deixaram de investir na continuidade e territorialidade de seu trabalho para se tornarem empresas especializadas na concorrência de verbas para espetáculos eventuais, o que envolvia a criação de boas redes de contatos junto à mídia e aos jurados de prêmios e editais. Isso certamente marcou a sociologia, a ética e a estética de todo um nicho de artistas brancos do centro e da zona sul da cidade, que viabilizavam seu experimentalismo artístico pela prática do empreendedorismo. Mas a ênfase curatorial na inovação cênica e no evento acabou desenhando um sistema teatral em que a intermitência dos trabalhos facilita a precarização e a desprofissionalização de atores e atrizes.

Com a crise econômica que se seguiu aos megaeventos esportivos e com a eleição de um prefeito fundamentalista religioso, a partir de 2016 praticamente todos os editais que fomentavam o teatro no Rio de Janeiro desapareceram ou foram reduzidos a pequenos cachês. Ainda restam apenas alguns editais e curadorias de instituições que patrocinam espetáculos dentro 
de seus próprios centros culturais. Mas com a virada político-ideológica do Brasil, mesmo esses espaços sofrem o avanço da censura institucional.

\section{Teatro social, identitário e/ou comunitário, via ONGs, grupos ou redes}

Desde a década de 90, o potencial de transformação social do teatro já vinha sendo explorado a ponto de gerar formas específicas de produção, através da atuação de organizações não-governamentais e de projetos sociais de cunho educativo. Para além dos critérios de sucesso do teatroentretenimento e de inovação do teatro-arte, um novo regime de legitimação havia surgido junto àqueles novos modos produtivos. Nesse novo regime, os projetos são valorados pelo impacto positivo em populações com baixos índices de desenvolvimento e/ou pouco acesso a políticas públicas. O regime social legitima o teatro que potencializa o desenvolvimento sustentável, o reconhecimento identitário e/ou a cultura da própria comunidade em seu entorno.

Através de políticas públicas ligadas à noção de democracia cultural, esse novo regime vinha sendo responsável por incluir o teatro pela primeira vez na vida de uma imensa camada da população, geralmente negra, favelada e sem acesso a serviços essenciais. Entretanto, os modos produtivos do teatro para o desenvolvimento enfrentam muitas dificuldades para integrar os artistas de favelas, de "minorias" ou de "periferias" à profissão ou a outros mundos teatrais da metrópole. Apesar disso, aos poucos o novo regime social de legitimação começou a influenciar também outros modos produtivos, como por exemplo o mundo dos editais, que passaram a incluir critérios tais como territorialidade, impacto social, questões de identidade, gênero e ancestralidade. De lá para cá, esse movimento de inclusão gerou novas cores, novos olhares e novas geografias para o meio teatral do Rio, a ponto de embaralhar a hierarquização cultural embutida no critério anterior, de inovação estética e excelência artística.

O resultado desse embaralhamento é que muitos grupos das chamadas "periferias" são, hoje, os que apresentam as propostas mais inovadoras e contundentes da cena carioca, e a questão social pode ficar 
muitas vezes em segundo plano na legitimação desses trabalhos. Neles, a cena tende a assumir aquilo que Óscar Cornago nomeia de caráter situacional, ao se voltar para o entorno, para o contexto, para o público, e tentar, dessa forma, fazer coincidir o social e o estético (CORNAGO, 2019). A partir de seu novo lugar de legitimação, esse teatro pode opor novas narrativas ao discurso hegemônico que separa centro e periferia, que insiste em querer nomear aqueles que podem produzir arte e aqueles que só podem produzir cultura.

Mas em 2016, tanto o lento e recente processo de democratização dos editais quanto o apoio estatal ao teatro para o desenvolvimento foram interrompidos pela crise econômica e pela virada política no país.

\section{Desprofissionalização, desencantamento}

Cada um desses meios de sustento definiu um ou mais modos produtivos que, por sua vez, arregimentaram e moldaram gerações de profissionais. Estes vêm de diferentes regiões da cidade, diferentes classes sociais e possuem diferentes escolaridades e identidades raciais. No ofício exercido em cada um desses meios, estes trabalhadores desenvolvem ideias, perspectivas, sensibilidades, engajamentos que também variam entre si. Desse processo de formação de mundos teatrais resultam valores de justiça muito distintos, que legitimam artistas, grupos e espetáculos por critérios diferentes.

O desencantamento é o signo comum a todos esses grupos de artistas que, hoje, veem suas atividades se desprofissionalizarem à medida que são abandonadas pelo Estado e pela sociedade. A sociologia pragmática (BOLTANSKI; THÉVENOT, 1991) afirma que o desencantamento pode ocorrer quando um indivíduo se vê julgado segundo valores que ele considera inautênticos. O economista e sociólogo do teatro Daniel Urrutiaguer (2014) descreve como artistas franceses que atuam através de diferentes políticas culturais se sentem desencantados por terem seus trabalhos julgados em uma escala de valores inadequada, muitas vezes emprestada de algum outro mundo teatral. 
Essa sensação de inadequação de valores também ocorre entre os mundos teatrais do Rio de Janeiro, alguns dos quais tentamos delinear aqui através do histórico de seus modos de produção. A extrema desigualdade social entre eles, a assimetria e estrangulamento de seus recursos aprofundam esse tipo de sentimento.

Em um sistema funcional, no qual um cardápio de políticas públicas e mercados diversos viabilizam uma variedade de modos produtivos, o intercâmbio de valores faz com que haja constantes mudanças nos regimes de legitimação de cada um deles. Daí a normalidade do sentimento de desencanto entre os diversos circuitos teatrais em todos os níveis - e no mundo inteiro. Enquanto for preservada uma certa variedade de políticas e de regimes de justiça, o desencanto estará sob controle, e será mesmo um sintoma da riqueza e da diversidade do campo cultural.

Mas quando um sistema teatral tende a pautar todos os seus circuitos por um mesmo padrão de sucesso empreendedor, quando hierarquiza esses nichos segundo o modelo conciliatório entre arte e indústria, o desencanto pode resultar em ressentimento. No Rio de Janeiro, um mesmo regime mercadológico de legitimação serve de parâmetro para nichos teatrais separados por enormes abismos sociais. Artistas começam e atuam em condições competitivas muito desiguais, configurando situações insuperáveis de injustiça. Nesse caso, a competição e a beligerância entre guetos teatrais segregados faz com eles não se misturem, não se influenciem e se acusem uns aos outros pela iniquidade e inoperância do sistema.

Ao contrário da década de 60, o teatro brasileiro se vê, hoje, abandonado, dividido e isolado, sem armas e sem organização para lutar a "guerra cultural" declarada contra ele por governos de extrema-direita e seus apoiadores. Especialmente no teatro do Rio de Janeiro, o maior legado da ideologia neoliberal que sucedeu a ditadura parece ter sido, portanto, seu efeito desmobilizador e despolitizante. 


\section{Apagão de fomentos: fundo do poço ou luz no fim do túnel?}

Apesar desse quadro desanimador, nos últimos anos alguns movimentos de cultura vêm surpreendentemente reunindo trabalhadores de teatro de todos os nichos, áreas geográficas e classes sociais do Rio. Estes movimentos podem misturar artistas famosos e ricos da TV e artistas favelados ou da periferia; artistas brancos que perderam seus editais recentemente e artistas negros que nunca tiveram acesso a esses editais.

Ao que parece, o presente apagão de políticas públicas pode estar criando uma janela de oportunidade para a interrupção da lógica de segregação no teatro do Rio de Janeiro. O corte abrupto e generalizado dos fomentos ao teatro, aliado ao declínio de garantias trabalhistas na indústria audiovisual, fez com que recentemente alguns setores antes incomunicáveis passassem a se unir em movimentos sociais até então impensados para a ecologia teatral do Rio. Ao levar às últimas consequências suas políticas de austeridade, a ideologia neoliberal pode estar preparando o terreno para uma reação contra ela mesma. Se o empreendedorismo se torna impossível, artistas se voltam ao ativismo cultural.

Paradoxalmente, a precarização total suspende algumas barreiras entre nichos teatrais, ao anular temporariamente a escala competitiva que hierarquiza seus modos de produção. A própria lógica individualista e empreendedora, que costura essa hierarquia, se desmantela junto com o ambiente competitivo que a abriga, diante da falta de horizonte para qualquer tipo de ascensão social dentro do meio artístico. A suspensão súbita de sentido para qualquer regime de justiça no teatro abre espaço assim para uma possível repolitização do meio.

Mas para que isso aconteça é preciso, antes, que a atual junção instintiva dos artistas que perderam tudo, ou quase tudo, se transforme em estratégia e sinergia através da articulação de suas diversas pautas. Somente a partir desse trabalho político é que governos e sociedade voltarão a respeitar e desejar o teatro enquanto usina de novas linguagens, mercados, ferramentas de educação e desenvolvimento, mão de obra para a indústria audiovisual etc. 
Novas estéticas, novas políticas, novos modos produtivos e de relação com o público podem ser propostos a partir dessa mobilização articulada. Deverão envolver estratégias mais coletivas de conciliação com a indústria audiovisual e uma atuação estatal maior e mais democrática no fomento à produção, ensino, pesquisa, distribuição e fruição do teatro.

Essa re-existência do teatro implica em uma mudança radical de mentalidade quanto às relações entre Estado, capital e cultura, e sua amplitude será aquela que o teatro, junto com outras artes, puder adquirir pela articulação política de todos os seus agentes. Lutar pela sobrevivência do teatro brasileiro é hoje, antes de tudo, lutar contra o individualismo que separa, aliena e desmobiliza seus trabalhadores. A desconstrução desse legado ideológico do pós-ditadura demanda muito mais do que a união das diversas castas artísticas. Ela solicita processos desierarquizantes que operem no sentido da dissolução dessas castas, começando pela demolição dos paradigmas elitistas e das barreiras sociais invisíveis. Ela exige de nós, artistas e pesquisadores, uma visão bem mais democrática de teatro e de sociedade, em que a produção e fruição do teatro e da cultura não se restrinjam ao privilégio de alguns, mas sejam um direito de todos.

\section{Referências bibliográficas}

BOLTANSKI, Luc; THÉVENOT, Laurent. De la justification: les économies de la grandeur. Paris : Gallimard, 1991.

CORNAGO, Óscar. ¿Y después de la performance qué? Público y teatralidad a comienzos del siglo XXI. Urdimento - Revista de Estudos em Artes Cênicas, Florianópolis, v. 1, n. 26, p. 020 - 041, 2016. Disponível em:

https://www.revistas.udesc.br/index.php/urdimento/article/view/14145731012620160 20. Acesso em: 9 jul. 2021.

GUENZBURGER, Gustavo. Rio, o teatro em movimentos: estética, política e modos de produção. Rio de Janeiro: Garamond, 2020.

URRUTIAGUER, Daniel. Les mondes du théâtre: désenchantement politique et économie des conventions. Paris : Harmattan, 2014. 